\title{
Confinement of concrete columns with unplasticized Poly-vinyl chloride tubes
}

Pramod Kumar Gupta

\begin{abstract}
In this paper an experimental study is presented to investigate the effectiveness of UPVC tube for confinement of concrete columns. UPVC tubes having $140 \mathrm{~mm}, 160 \mathrm{~mm}$ and $200 \mathrm{~mm}$ external diameters were used to confine the concrete having compressive strength $20 \mathrm{MPa}, 25 \mathrm{MPa}$ and $40 \mathrm{MPa}$. The concrete has been designed using IS code 10262-1982(Reaffirmed -2004) (BIS:10262-1982, Reaffirmed -2004). The testing of the specimens was carried out on a displacement controlled Instron make Universal Testing Machine of $2500 \mathrm{kN}$ capacity. During the experiments mode of deformation and corresponding load-compression curves were recorded and obtained results are compared with the existing models for confined concrete available in the literature. It is found that the predicted capacities of columns using different models are within $\pm 6 \%$ of the experimental capacities. It is found that UPVC tubes can be effectively used for confinement of the concrete columns and to enhance their load capacity, ductility as well as energy absorbing capacity.
\end{abstract}

Keywords: UPVC tube; Confined concrete columns; Confinement; Ductility

\section{Introduction}

Strengthening or repairing of deteriorating concrete columns has now become one of the areas of study in construction industry across the world. One of the deficiencies in concrete columns is the lack of lateral confinement and low energy absorption capacity (Schneider, 1998). Researchers are working on the techniques by which such deficiencies can be minimized during construction stage. The strength, ductility and energy absorption capacity of new concrete columns during construction can be enhanced by providing external confinement by employing UPVC tubes. These tubes can be used as formwork during construction and their after as an integral part of column. There are a number of confinement materials to be used for confining concrete columns. Structural steel tubes are extensively studied for such purpose in past two decades and as a result numerous literatures ((Oliveira et al. 2009); (Gupta et al. 2007)) are available.

Fiber reinforced polymer composite tubes are used for confinement of concrete by many researchers with performing experimental studies. Confined concrete columns having different length/diameter ratios were

Correspondence: spramod_3@yahoo.com

Department of Civil Engineering, I.I.T. Roorkee, Roorkee, India tested by Mirmiran \& Sahaway (1997). They also compared different analytical models suggested by different researchers for confinement of concrete and proposed a modified analytical model suitable exclusively for FRP tube confinement. Tao et al. (2004), Fitzwilliam \& Bisby (2010) and Bisby \& Ranger (2010) tested FRP-confined $\mathrm{RC}$ columns with a length/diameter ratio up to 20. Tamuzs et al. (2007a) also tested FRP-confined RC columns with a length/diameter ratio of 4 , but little slenderness effect existed in these columns as a result of their relatively small slenderness and end conditions. In addition, De Lorenzis et al. (2004) and Tamuzs et al. (2007b and 2008) tested slender FRP-confined concrete columns without steel reinforcement subjected to concentric compression to investigate the solidity of these columns.

A very few studies are available in which PVC tubes are used for confinement of concrete column specimens. Way back Kurt (1978) conducted experiments to see increase and decrease in strength of concrete core due to confinement and slenderness ratio respectively. In last one decade Marzouck \& Sennah (2002) conducted experimental study on concrete filled PVC tubes with $100 \mathrm{~mm}$ diameter concrete core and $3 \mathrm{~mm}$ thickness of tube. The lengths of to the concrete columns. They reported that as the slenderness ratio increases, the

\section{Springer}

C 2013 Gupta; licensee Springer. This is an Open Access article distributed under the terms of the Creative Commons Attribution License (http://creativecommons.org/licenses/by/2.0), which permits unrestricted use, distribution, and reproduction in any medium, provided the original work is properly cited. 
Table 1 Physical properties of UPVC pipes

\begin{tabular}{cc}
\hline Parameter & Value \\
\hline Density & $13-14.5 \mathrm{KN} / \mathrm{m}^{3}$ \\
Elastic modulus & $3380 \mathrm{MPa}$ \\
Flexure strength & $65.5 \mathrm{MPa}$ \\
Poisson ratio & 0.38 \\
Ultimate tensile strength & $27.5-52 \mathrm{MPa}$ \\
Breaking elongation & $134 \%$ \\
Thermal conductivity & $0.14-0.28 \mathrm{kcal} / \mathrm{m} \cdot \mathrm{hr}^{\circ} \mathrm{C}$ \\
Service life & $>50$ years \\
\hline
\end{tabular}

tubes were 758, 562, 416 and $270 \mathrm{~mm}$. They found that the PVC tube provides significant lateral confinement compressive strength of concrete filled PVC tube decreases.

In view of these facts, in the present study the author has tried to strengthen the concrete column by using the UPVC tube as outer confining layer in order to increase the load carrying capacity, ductility and durability of the column. A comparative test research program to strengthen columns by UPVC tube has been put forward. In order to evaluate the behaviour of the proposed UPVC tube columns more objectively and thoroughly, an experimental study is performed. The test results are presented and discussed from strength, ductility and energy absorption capacity point of view. Since use of UPVC for confinement of concrete is relatively new and theoretical work available in this area is very limited. Therefore, different theoretical models available in literature that were originally proposed for confinement developed by other means are used to assess the confinement of the concrete columns with UPVC tubes.

\section{Experimental programme \\ Materials}

Un plasticized Poly Vinyl Chloride (UPVC) Tube

In this paper, Un-plasticized Poly-Vinyl-Chloride (UPVC) was chosen to confine concrete after considering following points

1. Polymer is one of the most stable substances when high corrosion resistance is required. The anti-corrosion characteristics of UPVC have been proven to be outstanding. Since the last century, polyethylene copolymer coatings have been used of

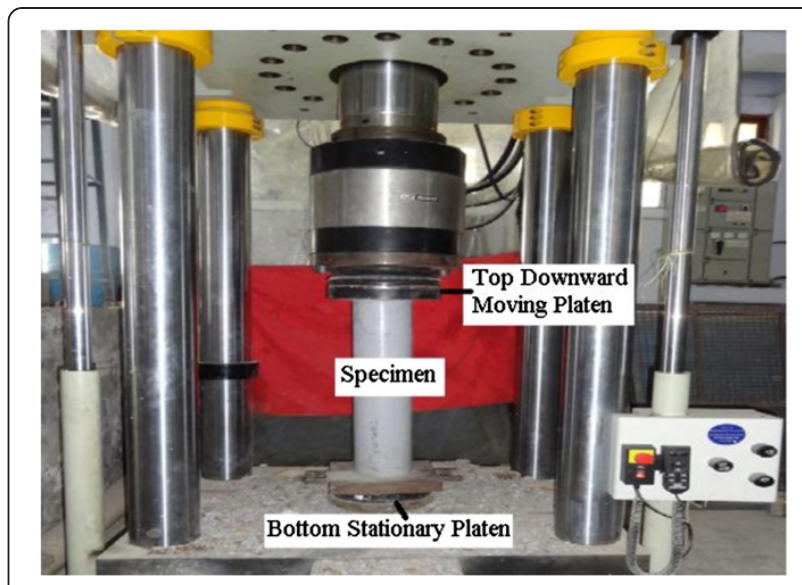

Figure 1 Test-setup for performing experimental study.

the protection of external surface of onshore and offshore pipelines.

2. UPVC tube can also be used as a protective layer against mechanical damage caused by the severe environment. Physical properties of the UPVC are given in Table 1 . The thermal conductivity of UPVC is only $0.45 \%$ that of a steel tube; it can provide a stable curing condition for the core concrete to achieve high performances and high durability. It can withstand those mechanical damages which occur in the exposure of high energy environments like marine and saline.

Finally the service life of UPVC tube is longer than 50 years, and with the mechanical supporting of core concrete UPVC can serve longer as a protective layer of the concrete structure.

\section{Concrete}

Three series of concrete M20, M25, M40 were designed as per code IS:10262-1982 (Reaffirmed -2004) (BIS:102621982, Reaffirmed-2004) to fill the UPVC tubes. Portland Pozzolona Cement (according to IS1489-1991 Part-1) was used to obtain concrete. Its compressive strength was 20 $\mathrm{MPa}$ at 3 days and $45 \mathrm{MPa}$ at 28 days. Local sand with a fineness modulus of 2.7 was used as fine aggregate and saturated surface dry crushed aggregate was used as coarse aggregate. The concrete mix proportions and the compressive strength at 28 days are given in Table 2 .

Table 2 Concrete mixture proportions

\begin{tabular}{|c|c|c|c|c|c|c|}
\hline Grade of mix & Water/cement ratio & Water $\left(\mathrm{Kg} / \mathrm{m}^{3}\right)$ & Cement $\left(\mathrm{Kg} / \mathrm{m}^{3}\right)$ & Sand $\left(\mathrm{Kg} / \mathrm{m}^{3}\right)$ & Aggregate $\left(\mathrm{Kg} / \mathrm{m}^{3}\right)$ & $\begin{array}{l}\text { Compressive strength } \\
\text { at } 28 \text { days } \mathrm{f}_{\mathrm{ck}}(\mathrm{MPa})\end{array}$ \\
\hline M20 & 0.50 & 215 & 428 & 619 & 1040 & 23.6 \\
\hline M25 & 0.47 & 215 & 458 & 564 & 1033 & 28.6 \\
\hline M40 & 0.40 & 215 & 537 & 590.7 & 934.5 & 43.5 \\
\hline
\end{tabular}


Table 3 Details of specimens

\begin{tabular}{|c|c|c|c|c|}
\hline Specimen & $\mathrm{D} / \mathrm{t}$ ratio & $\mathrm{D} \times \mathrm{t} \times \mathrm{L} \mathrm{mm}$ & Confinement parameter $a=\frac{A_{p} f_{p y}}{A_{c} f_{c k}}$ & Residual strength at $30 \mathrm{~mm}$ compression as $\%$ of peak load \\
\hline T160M20PC-1 & 37.6 & $160 \times 4.25 \times 500$ & 0.20 & 42.2 \\
\hline T160M20PC-2 & 37.6 & $160 \times 4.25 \times 500$ & 0.20 & 49.9 \\
\hline T200M20PC-1 & 34.1 & $200 \times 5.85 \times 500$ & 0.23 & 44.4 \\
\hline T200M20PC-2 & 34.1 & $200 \times 5.85 \times 500$ & 0.23 & 54.1 \\
\hline T140M25PC-1 & 35.8 & $140 \times 3.9 \times 500$ & 0.17 & 45.2 \\
\hline T140M25PC-2 & 35.8 & $140 \times 3.9 \times 500$ & 0.17 & 45.05 \\
\hline T140M40PC-1 & 35.8 & $140 \times 3.9 \times 500$ & 0.11 & 42.70 \\
\hline T140M40PC-2 & 35.8 & $140 \times 3.9 \times 500$ & 0.11 & 42.70 \\
\hline
\end{tabular}

\section{Testing of specimens}

Eight UPVC tubes with the outer diameters (D) of 140 $\mathrm{mm}, 160 \mathrm{~mm}$ and $200 \mathrm{~mm}$ were cut in $500 \mathrm{~mm}$ length (L). The wall thickness ( $\mathrm{t}$ ) of UPVC tubes were $3.9 \mathrm{~mm}$, $4.25 \mathrm{~mm}$ and $5.85 \mathrm{~mm}$ for $140 \mathrm{~mm}, 160 \mathrm{~mm}$ and 200 $\mathrm{mm}$ diameters respectively. Typical nomenclatures for specimens are used to designate them. For example specimen T160M20PC-1: T160 - stands for tube of $160 \mathrm{~mm}$ external diameter, M20 - stands for grade of concrete, PC - stands for Plain concrete, 1-stands for first specimen. Therefore, T160M20PC-1 indicates specimen made with tube of diameter $160 \mathrm{~mm}$, filled with plain concrete having compressive strength $20 \mathrm{MPa}$ and number one. The test setup used for performing experiments is shown in Figure 1. The stress-strain curves of specimens were obtained by performing compression tests on INSTRON make UTM machine with a capacity of $2500 \mathrm{KN}$. The experiment was performed using a displacement control method with cross head speed of $1 \mathrm{~mm} / \mathrm{min}$. The upper jaw of the machine was moved in the downward direction while bottom jaw was kept stationary. The rate was applied continuously without a jerk load. Loads and displacements were measured continuously by data collection computer system. The frequency of the data collection is $0.4 \mathrm{~Hz}$.

Details of column specimens are given in Table 3. To judge the confinement effect of UPVC tube constraining factor $\alpha$ was applied and defined as (Golla 2012, Lakumalla 2012, Wang \& Yang, 2010);

$$
\alpha=\frac{A_{p} f_{p y}}{A_{c} f_{c k}}
$$

where Ap and fpy are the cross-sectional area and yield stress of UPVC tube, repectively; and Ac and fck are the area and compressive strength of the core concrete respectively. UPVC tubes were tested for the tensile strength of their material with the sample as shown in Figure 2. This sample was tested in the TINIUS OLSEN machine of the material testing laboratory of Metallurgy Department of Indian Institute of Technology Roorkee with a loading rate of $50 \mathrm{~mm} / \mathrm{min}$. Figure 2(b) shows the original sample used for the testing. The stress-strain curve is shown in Figure 3(a). The ultimate strength (fpy) was recorded as 42.22 $\mathrm{MPa}$. Figure 3(b) shows the arrangement for testing of pipes to determine bursting water pressure. The bursting pressure can be used as confining pressure for core concrete.

The axial displacement of all specimens was controlled in the range from 0 to $30 \mathrm{~mm}$. It was found that the residual strengths of all specimens were still greater than $42 \%$ of peak load at the axial displacement of $30 \mathrm{~mm}$ (see Table 3).

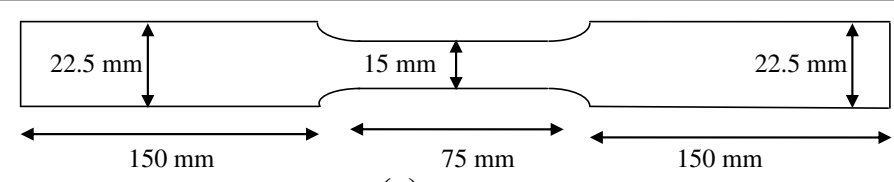

(a)

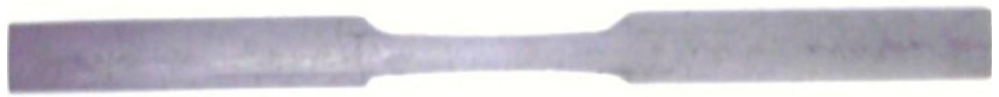

(b)

Figure 2 Typical specimen for tension test of UPVC tube (a) Dimensions, (b) Photograph. 


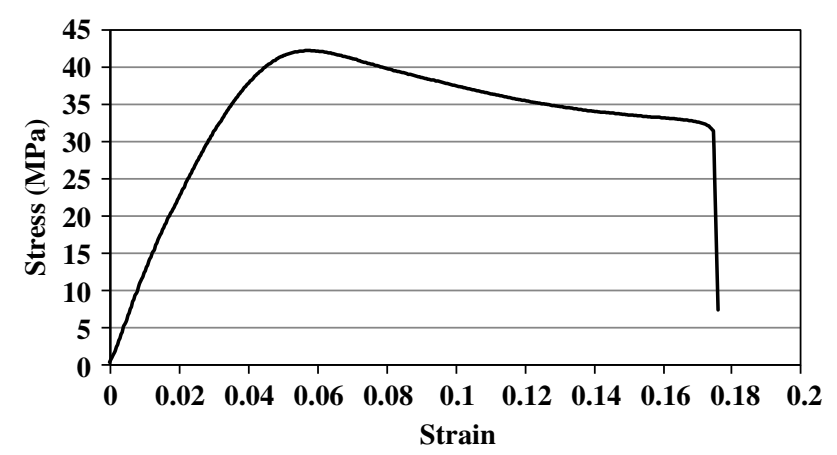

(a)
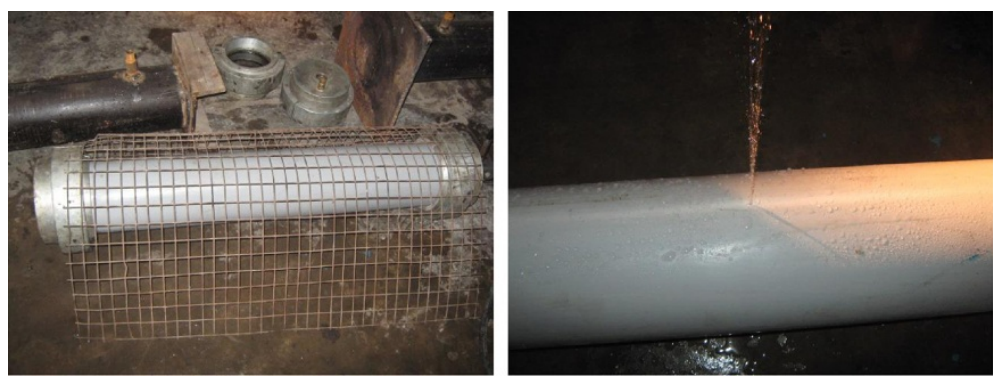

(b)

Figure 3 (a) Typical tensile stress-strain curve of UPVC tube material. (b) Typical testing arrangement to find brusting (confining) pressure for UPVC pipes.

\section{Experimental results and discussions} Mode of failure

All specimens exhibited a good ductility and still retained the integrity when the displacement reached $30 \mathrm{~mm}$. The failure pattern of all specimens was shear failure as shown in Figure 4(a-d). A typical characteristic of shear failure is that the core concrete is damaged by shear stress in one direction due to weak confinement effect of the tube. The shear crack direction can be judged by the appearance of the specimen. The same type of mode of failure was also observed by Wang \& Yang (2010) in their experimental program. They also found shear type failure for specimens having $\alpha \leq 0.204$. For all specimens tested here $\alpha$ is between 0.11 and 0.23 . (see Table 3). Shear failure is brittle type failure. To avoid the shear failure of the specimens, the diameter to wall thickness ratio ( $\mathrm{D} / \mathrm{t}$ ratio) of the tube should be taken sufficiently lower.

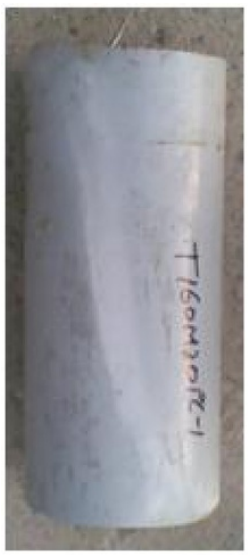

(a)

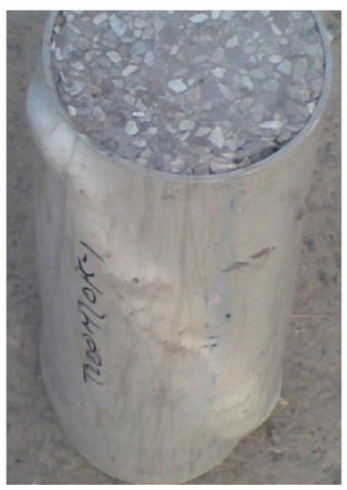

(b)

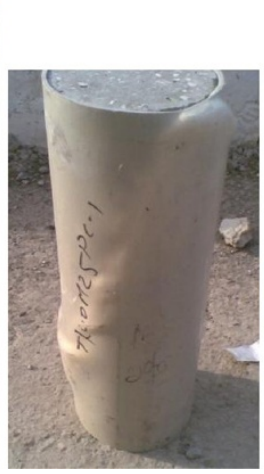

(c)

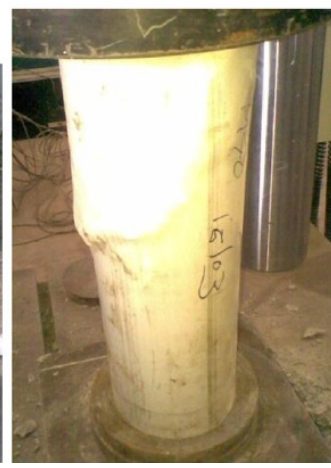

(d)

Figure 4 Typical failure modes of specimens: (a) T160M20, (b) T200M20, (c) T140M25, (d) T140M40. 


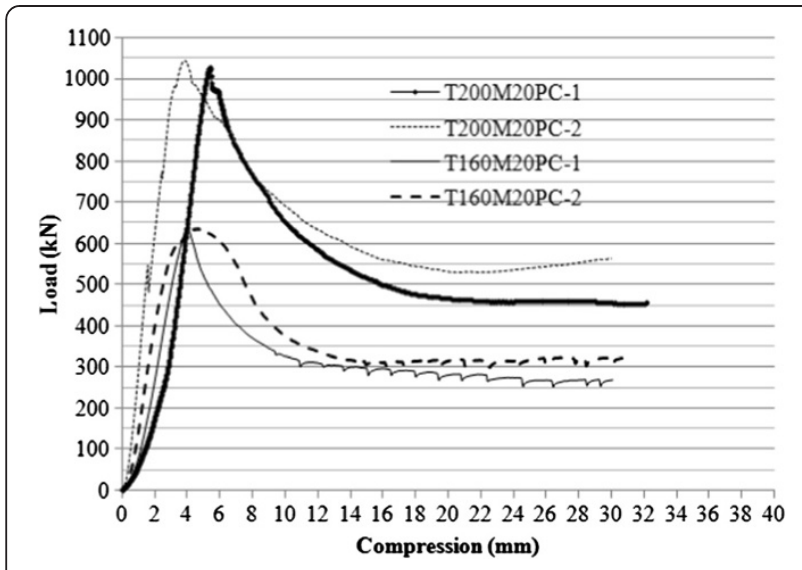

Figure 5 Comparison of load-compression variations of different diameter tubes filled with same concrete grade M20.

\section{Load-compression curve}

Figures 5 and 6 show the load-compression curves of all the specimens. Load-compression curves are classified according to the specimens with the same core concrete and different tubes, or with the same tube and different core concretes respectively.

From Figure 5 it is clear that as diameter of tube increases the peak load increase but the ductility decreases for the specimens having different diameters and filled with concrete having same compressive strength. From Figures 5 and 6 it is also clear that the tube diameter to thickness ratio $(\mathrm{D} / \mathrm{t})$ affects the post-peak behaviour of the curve. The absolute values of the slope of the curves decline by the decrease in tube diameter/thickness ratio, where as the change of the residual strength ratios of the specimens after peak stress is generally just the opposite. The reason is that the confinement effect of UPVC tube enhances as the tube thickness increases and confined concrete shows enhanced ductility.

It can be found from Figure 6 that the slope of the onset section of the curves goes down with the decrease in grade of concrete. The reason can be attributed to the

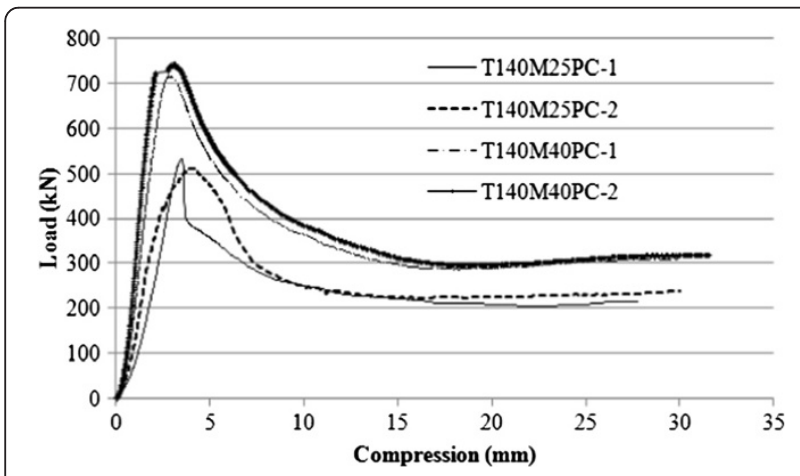

Figure 6 Comparison of load-compression variations of same diameter tubes filled with different concrete grades.

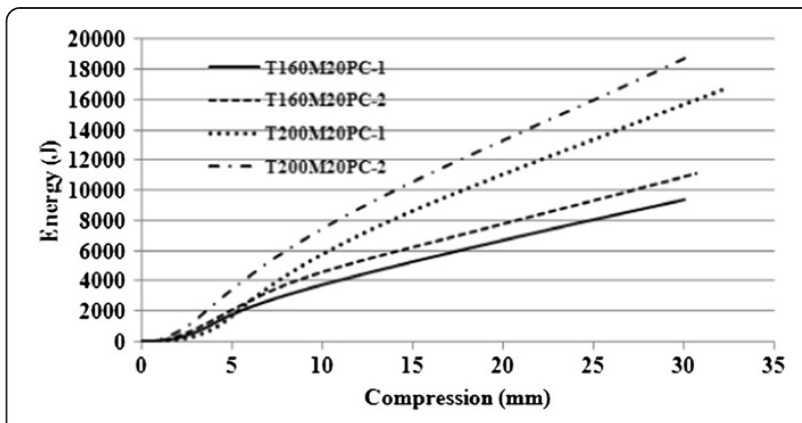

Figure 7 Comparison of energy-compression variations of different diameter tubes filled with same concrete grade M20.

difference of the elastic modulus between UPVC tube and core concrete. The elastic modulus of UPVC tube is only between $9 \%$ and $15 \%$ that of the concrete core. Therefore, when the grade of concrete decreases; the proportion of UPVC elastic modulus in a confined concrete specimen increases; and the elastic modulus of the confined concrete decreases.

From Figure 6 it is also clear that concrete strength affects the post-peak behaviour of the curve significantly. Absolute values of the slope of the curve increase with increase in concrete strength because the core concrete becomes more brittle. The residual strength of specimen decreases with increase in concrete strength.

Figures 7 and 8 shows the energy-compression curves for different specimens. It is clear from Figure 7 that as diameter of tube increases the energy absorbing capacity also increases.

\section{Ductility}

To assess the confinement effect on the ductility and energy absorbing capacity of the specimens, the ductility ratios and energy absorbing ratios of all of the column specimens were calculated and the results are tabulated in Table 4. According to (Wu, 2004), ductility can be assessed by the ductility ratio $\mu$, which is defined as the ratio of displacement. The ductility ratio at different

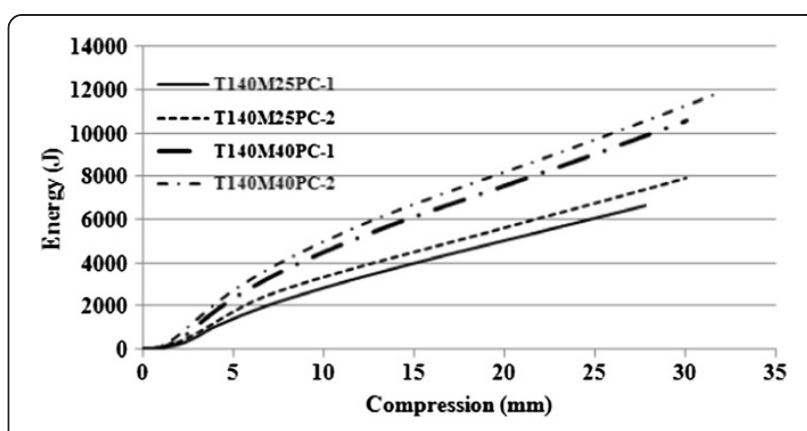

Figure $\mathbf{8}$ Comparison of energy-compression variations of same diameter tubes filled with different concrete grades. 
Table 4 Details of experimental results in terms of displacement, ductility ratios $\mu$, energy absorption and energy absorption ratio $\xi$

\begin{tabular}{|c|c|c|c|c|c|c|c|c|c|c|c|c|c|c|c|}
\hline \multirow[t]{3}{*}{ Specimen } & \multirow{3}{*}{$\begin{array}{l}\text { Ultimate } \\
\text { load (kN) }\end{array}$} & \multicolumn{5}{|c|}{ Axial displacement (mm) } & \multicolumn{2}{|c|}{ Ductility ratio } & \multicolumn{5}{|c|}{ Energy absorbed (Jule) } & \multicolumn{2}{|c|}{ Energy ratio } \\
\hline & & & & & & & \multirow{2}{*}{$\frac{\mu_{=} \Delta_{u} / \Delta_{y}}{1.03}$} & \multirow{2}{*}{$\frac{\mu_{70=} \Delta_{70} / \Delta_{y}}{2.65}$} & \multirow[b]{2}{*}{$\mathrm{E}_{\mathrm{u}}$} & \multirow[b]{2}{*}{$\mathrm{E}_{90}$} & \multirow[b]{2}{*}{$E_{80}$} & \multirow[b]{2}{*}{$\mathrm{E}_{70}$} & \multirow[b]{2}{*}{$\mathrm{E}_{\mathrm{y}}$} & \multirow[t]{2}{*}{$\xi=E_{u} / E_{y}$} & \multirow[t]{2}{*}{$\xi_{70}=E_{70} / E_{y}$} \\
\hline & & $\Delta_{\mathbf{u}}$ & $\Delta_{90}$ & $\Delta_{80}$ & $\Delta_{70}$ & $\Delta_{\mathrm{y}}$ & & & & & & & & & \\
\hline T160M20PC-1 & 638 & 4.02 & 4.52 & 5.86 & 10.35 & 3.9 & 1.31 & 3.74 & 1172 & 1478 & 2163 & 3846 & 1150 & 1.02 & 3.34 \\
\hline T160M20PC-2 & 640 & 4.7 & 6.65 & 8.15 & 13.48 & 3.6 & 1.28 & 3.56 & 1840 & 3031 & 3803 & 5725 & 1154 & 1.59 & 4.96 \\
\hline T200M20PC-1 & 1026 & 5.37 & 6.17 & 8.45 & 14.96 & 4.2 & 1.27 & 6.74 & 2072 & 2841 & 4703 & 8628 & 1025 & 2.02 & 8.42 \\
\hline T200M20PC-2 & 1044 & 3.83 & 5.22 & 8.27 & $20.35 / 30$ & 3.02 & 1.01 & 1.40 & 2221 & 3586 & 6187 & 13515 & 1403 & 1.58 & 9.63 \\
\hline T140M25PC-1 & 530 & 3.52 & 3.63 & 4.62 & 4.88 & 3.49 & 0.92 & 1.96 & 800 & 861 & 876 & 1238 & 800 & 1.00 & 1.55 \\
\hline T140M25PC-2 & 511 & 3.06 & 5.3 & 5.94 & 6.5 & 3.32 & 1.01 & 1.95 & 1231 & 1831 & 2114 & 2322 & 855 & 1.44 & 2.72 \\
\hline T140M40PC-1 & 714 & 2.96 & 3.85 & 4.58 & 5.68 & 2.92 & 1.29 & 2.48 & 1076 & 1679 & 2120 & 2703 & 1042 & 1.03 & 2.59 \\
\hline T140M40PC-2 & 742 & 3.06 & 3.99 & 4.76 & 5.88 & 2.37 & 1.03 & 2.65 & 1397 & 2059 & 2544 & 3165 & 800 & 1.55 & 3.52 \\
\hline
\end{tabular}

stages of load-compression curve is calculated to ascertain the behaviour of the specimens during axial compression.

$$
\mu_{0}=\frac{\Delta U}{\Delta Y}, \quad \mu_{90}=\frac{\Delta 90}{\Delta Y}, \quad \mu_{80}=\frac{\Delta 80}{\Delta Y}, \quad \mu_{70}=\frac{\Delta 70}{\Delta Y}
$$

Where $\Delta U$ is the Ultimate displacement at Ultimate strength and $\Delta \mathrm{Y}$ is the Yield displacement at yield point. The ultimate axial displacement $\Delta U$ is defined as the point at which the load is maximum (peak) and designated as $\mathrm{Pu}$. The other load levels are defined with the loads equivalent to $90 \%, 80 \%$ and $70 \%$ of maximum load and designated as $0.9 \mathrm{Pu}, 0.8 \mathrm{Pu}$ and $0.7 \mathrm{Pu}$. The displacements corresponding to these load levels are designated as, $\Delta 90, \Delta 80$ and $\Delta 70$ respectively. The yield displacement $\Delta \mathrm{Y}$ is the yield point of an equivalent bilinear response curve that provides an equal area to that of the envelope curve, as shown in Figure 9. The ductility ratios at different load levels are calculated and summarised in Table 4.

The energy absorption capacity of the composite system indicates the effectiveness of the UPVC confinement. The

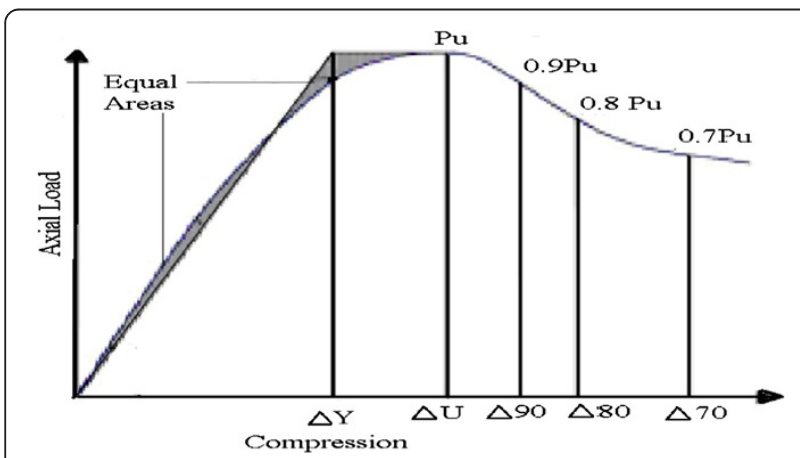

Figure 9 Definition of Ductility and load capacity at different stages of load-Compression curve. energy absorption ( $E$ in Joules) was calculated by finding the area under the load-compression curve upto different load levels.

The ductility ratios $\mu$ and the energy absorption $E$ of all specimens were calculated and the results are shown in Table 4 . It can be seen from Table 4 that $\mu_{0}$ and $\mu_{70}$ are higher for richer mixes (Sp. T140M40PC) as compared to lean mixes (Sp. T140M25PC). Moreover, the percentage residual strength of specimen T140M40PC is lower than of specimen T140M25PC. This shows that in the initial stage of compression, ductility is higher and turns lower in the advance stage of loading for specimen T140M40PC. The ductility ratio $\mu_{70}$ for specimens varies between 1.4 and 6.74. On the other hand energy ratio $\xi_{70}$ varies between 1.55 and 9.63 . The ductility ratio $\mu_{0}$ for specimens varies between 1.01 and 1.31. The corresponding energy absorption ratio $\xi_{0}$ varies between 1.0 and 2.02. It is also clear from Table 4 that as $\mathrm{D} / \mathrm{t}$ ratio of the UPVC tube decreases the ductility and energy absorbing capacity increases in general and consequently $\Delta_{0}, \Delta_{50}, \Delta_{70}, \Delta_{80}$ and $\xi_{0}, \xi_{50}, \xi_{70}$ and $\xi_{80}$ increases.

It can be seen from Table 4 that generally the ductility ratio $\mu$ decreases with increase in grade of concrete due to the brittleness of core concrete. The energy absorption $\mathrm{E}$ increases with increase of concrete strength which is obvious.

\section{Confinement}

\section{Confinement modeling}

The confinement provided by transverse reinforcement, external jacket, steel tube and UPVC tube is of a passive type. The confining pressure is developed only after the surrounding member undergoes hoop elongation (Poisson's effect in concrete). The mechanics of confinement is therefore dependent mainly on two factors, one the tendency of concrete to dilate and second the radial stiffness of the confining member to restrain the dilation. Therefore, two conditions which are strain compatibility 
Table $\mathbf{5}$ Comparison of experimental capacity in $\mathbf{k N}$ with the predicted capacity with models

\begin{tabular}{|c|c|c|c|c|c|c|}
\hline Specimens & Experimental & Richart, et al. & Newmn \& newman & Mander et. Al & Ahmad \& shah & Saatcioglu and razvi \\
\hline T160M20PC-1 & 638.8 & 598.1 & 640.9 & 663.8 & 604.7 & 669.7 \\
\hline T160M20PC-2 & 640.4 & 598.1 & 640.9 & 663.8 & 604.7 & 669.7 \\
\hline T200M20PC-1 & 1026.2 & 960.7 & 1029.1 & 1066.7 & 972 & 1076.3 \\
\hline T200M20PC-2 & 1044.3 & 960.7 & 1029.1 & 1066.7 & 972 & 1076.3 \\
\hline T140M25PC-1 & 530.2 & 520.7 & 557.3 & 575.6 & 525.5 & 574.6 \\
\hline T140M25PC-2 & 511.7 & 520.7 & 557.3 & 575.6 & 525.5 & 574.6 \\
\hline T140M40PC-1 & 714.0 & 725.1 & 771.7 & 789.9 & 730 & 779 \\
\hline T140M40PC-2 & 742.6 & 725.1 & 771.7 & 789.9 & 730 & 779 \\
\hline
\end{tabular}

between the concrete core and the UPVC tube as well as equilibrium of forces in the free-body diagram for any sector of the confined section must always be satisfied.

In past, researchers have attempted to develop a generalized model to quantify the effects of confinement on strength and ductility of concrete. Among the models developed till now, the one proposed by Mander et al. (1988) is most widely used. This model was originally developed for conventional reinforced-concrete (RC) columns. A more theoretical approach was taken by Ahmad \& Shah (1982) whose model is proved effective for conventional RC columns. In this section, these models are compared in terms of the basic characteristics of UPVC tube confinement.

Confinement effectiveness is defined as ${ }^{f}{ }_{c c} / f^{\prime} c o$ where $f_{c c}^{\prime}=$ compressive strength of confined concrete, $f_{c o}^{\prime}=$ compressive strength of unconfined concrete. The confining pressure $f_{r}$ can be calculated with the internal diameter $\left(D_{\text {int }}\right)$, tensile strength $\left(f_{\mathrm{py}}\right)$ and wall thickness (t) of the UPVC tube;

$$
f_{r}=\frac{2 f_{p y} t}{D_{\text {int }}}
$$

The confining pressures for different pipes were also obtained experimentally. Figure 3(b) shows the arrange-

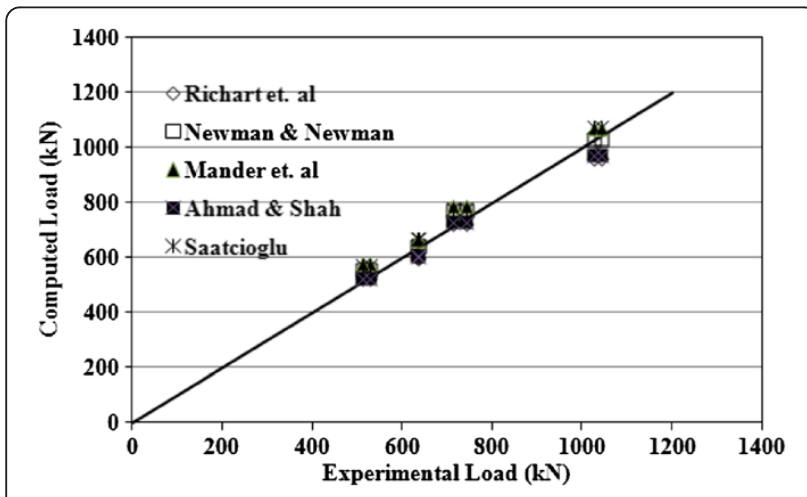

Figure 10 Graphical Representation of experimental and predicted load capacity of different specimens. ment for the hydrostatic pressure test. It was observed that the values were comparable with the obtained values using Equation (3). The confining pressure obtained with experiments and Equation (3) can be used to obtain the load carrying capacity of specimens using different models because the axial compressive strain at peak load shall be very small (of the order of 0.002-0.004) and UPVC tube shall not contribute in axial stiffness at this small strain.

Richart et al. (1928) suggested the following relationship between confinement effectiveness and the confinement ratio $f_{r} / f_{c o}$

$$
f^{\prime c c} /_{f_{c o}^{\prime}}=1+k_{1}\left(f_{r} / f_{c o}\right)
$$

where $k_{1}=4.1=$ effectiveness coefficient. Newman \& Newman (1971) suggested the following nonlinear relationship, since confinement is not effective at high levels of lateral pressure:

$$
k_{1}=3.7\left(f_{r} / f_{c o}\right)^{-0.14}
$$

More recently, Saatcioglu \& Razvi (1992) suggested the following coefficient based on the test data from Richart et al. (1928):

$$
k_{1}=6.7\left(f_{r}\right)^{-0.17}
$$

The model proposed by Mander et al. (1988) suggests a nonlinear relationship based on the ultimate strength surface developed by Elwi \& Murray (1979), which reduces to the following form for circular sections:

$$
f_{c c} f_{f_{c o}}=\left(2.254 \sqrt{\left(\left(1+7.94 f_{r} / f_{c o}\right) \cdot-2 f_{r} / f_{c o}-1.254\right)}\right.
$$

Ahmad \& Shah (1982) model uses a strength criterion based on the octahedral failure theory, the three stress invariants, and test data for reinforced concrete specimens, solving the octahedral equations for the confined strength of concrete, the model can be given as; 


$$
\begin{aligned}
& f_{c c}^{\prime} /_{f_{c o}}=\left(1+4.2556^{f r} / f_{c o}\right) \quad \text { if } f_{r} / f_{c o}<0.68 \\
& f^{\prime} c c / f_{i o}=\left(1.7757+3.1171^{f r} / f^{\prime c o}\right) \text { if } f_{r} / f_{i c} \\
& >0.68
\end{aligned}
$$

Table 5 presents the comparison of experimental load capacity of all specimens with the predicted ones using above discussed different models. It is clear that the predicted capacities are within $\pm 6 \%$ of the experimental capacities. The graphical representation of the predicted load capacities and experimental ones are depicted in Figure 10. It can be concluded from Figure 10 and Table 5 that the model proposed by Richart et al. (1928) predicts conservative capacities. On the other hand model proposed by Saatcioglu \& Razvi (1992) calculates capacities on higher side.

\section{Conclusions}

This paper proposes a new kind of composite column, which is obtained by filling unplasticized Poly-Vinyl Chloride (UPVC) tube with concrete. Based on the test results following conclusions may be drawn;

1. Confinement of concrete columns with UPVC tubes improves their compressive strength and ductility.

The improvement in strength and ductility is dependent on the concrete strength and geometrical properties of the tubes.

2. Failure pattern of all the specimens are shear type failure.

3. Confinement effect of UPVC is compared with already developed models in the literature and results are varying within $\pm 6 \%$.

4. Compressive strength of concrete affects the post-peak behaviour of the load-compression curve significantly. Absolute value of the slope of the curve increases with increase in concrete strength due to the increased brittleness.

5. The slope of the onset section of the curves goes down with decrease in grade of concrete.

6. The tube diameter/thickness ratio affects the post-peak behaviour of the curve; Absolute value of the slope of the curve declines by decrease in tube diameter/ thickness ratio.

\section{Competing interests}

The author declare that he has no competing interests.

\section{Acknowledgements}

Financial support provided by Building Materials \& Technology Promotion Council (BMTPC), Ministry of Housing \& Urban Poverty Alleviation, Government of India for this research work is acknowledged. Author is also thankful to his masters' students Golla Ramesh and Nagraju Lakumalla for conducting experiments.

Received: 16 February 2013 Accepted: 19 August 2013

Published: 30 Aug 2013

\section{References}

Ahmad SH, Shah SP (1982) Complete triaxial stress-strain curves for concrete, ASCE. J Struct Engrg 108(4):728-742

BIS: 10262-1982 (Reaffirmed-2004) Recommended guidelines for concrete mix design. Bureau of Indian Standards, New Delhi, India

Bisby LA, Ranger M (2010) Axial-flexural interaction in circular FRP confined reinforced concrete columns. Construct Build Mater 24(9):1672-1681

De Lorenzis L, Tamuzs V, Tepfers R, Valdmanis V, Vilks U (2004) Stability of CFRP-confined columns. In: Proceedings, First International Conference on Innovative Materials and Technologies for Construction and Restoration, 6-9 June, 2004. Universita degli Studi di, Lecce, Italy, pp 327-342

Elwi AA, Murray DW (1979) A 3D hypoelastic concrete constitutive relationship. J Engrg Mech ASCE 105(4):623-641

Fitzwilliam J, Bisby LA (2010) Slenderness effects on circular CFRPconfined reinforced concrete columns. Journal of Composites for Construction, ASCE 14(3):280-288

Golla R (2012) Experimental investigation into behaviour of concrete filled PVC tubes. M. Tech. dissertation. Indian Institute of Technology, Roorkee, India

Gupta P, Sarda S, Kumar M (2007) Experimental and computational study of concrete filled steel tubular columns under axial loads. J Constructional Steel Research 63:182-193

Kurt CE (1978) Concrete filled structural plastic columns. J Str Division 104(no. ST1): pp. 55-63

Lakumalla N (2012) Study on reinforced cement concrete filled UPVC pipes as columns. (M. Tech. dissertation 2012). Indian Institute of Technology Roorkee, Roorkee, India

Mander J, Priestley MJ, Park RJ (1988) Theoretical stress-strain model for confined concrete. J Struct Engrg, ASCE 114(8):1804-1826

Marzouck M, Sennah K (2002) Concrete filled PVC tubes as compression members. Proc. International congress on challenges of concrete construction at Scotland, U.K

Mirmiran A, Sahaway M (1997) Behaviour of Concrete columns Confined by Fiber Composites. Journal of Structural Engineering ASCE 125(5):583-590

Newman K, Newman JB (1971) Failure theories and design criteria for plain concrete. Proc. Int. Civ. Engrg. Mat. Conf. on Struct., Solid Mech. and Engrg. Des. Wiley Interscience, New York, pp pp. 936-995

Oliveira W, Nardin S, Debs A, Debs M (2009) Influence of concrete strength and length/diameter on the axial capacity of CFT columns. J Constructional Steel Research 65:2103-2110

Richart FE, Brandtzaeg A, Brown RL (1928) A study of the failure of concrete under combined compressive stresses. Engg. Experimental Station Bull. No. 185. University of Illinois, Urbana III

Saatcioglu M, Razvi SR (1992) Strength and ductility of confined concrete. J Struct Engrg, ASCE 118(6):1590-1607

Schneider SP (1998) Axially loaded concrete filled steel tubes. J Str Engg 124(10):1125-1138

Tamuzs V, Valdmanis V, Gylltoft K, Tepfers R (2007a) Behavior of CFRPconfined concrete cylinders with a compressive steel reinforcement. Mech Compos Mater 43(3):191-202

Tamuzs V, Tepfers R, Zile E, Valdmanis V (2007b) Stability of round concrete columns confined by composite wrappings. Mech Compos Mater 43(5):445-452

Tamuzs V, Valdmanis V, Tepfers R, Gylltoft K (2008) Stability analysis of CFRP-wrapped concrete columns strengthened with external longitudinal CFRP sheets. Mech Compos Mater 44(3):199-208

Tao Z, Teng JG, Han LH, Lam L (2004) Experimental behaviour of FRPconfined slender RC columns under eccentric loading. In: Proceedings, Second International Conference on Advanced Polymer Composites for Structural Applications in Construction, University of Surrey, Guildford, UK., pp 203-212

Wang J, Yang Q (2010) Experimental study on Mechanical Properties of concrete confined with plastic Pipe. Title no. 107-M17. ACI Mater J: 107,132-137

Wu YF (2004) The Effect of Longitudinal Reinforcment on the Cyclic Shear Behaviour of Glass Fiber Reinforced Gypsum Wall Panels:Tests. Eng Struct 26(11):1633-1646

10.1186/2008-6695-5-19

Cite this article as: Gupta: Confinement of concrete columns with unplasticized Poly-vinyl chloride tubes. International Journal of Advanced Structural Engineering 2013, 5:19 